\section{The Furthest Depths of Space}

THE theory of the expanding universe, which has lately attracted so much attention, formed the principal topic of Sir James Jeans's remarks in the Henry Sidgwick memorial lecture for 1932, which was given at Newnham College, Cambridge, on November 26, under the title "The Furthest Depths of Space". In a brief survey, Sir James introduced his listeners to the universe as we know it to-day, beginning with the naked-eye stars, then passing to the Milky Way system and from there to the extragalactic nebulæ. These, in themselves objects of great importance, acquire additional interest as straws floating in the stream of space, showing how its currents are flowing. This space is curved, with a texture varying from the local irregularities which cause the electron to twist about in an electric or magnetic field, or the planets to move in curved orbits around the sun, to a bigger, coarser texture which makes space curve round on itself and finally close up. The state of curvature is not quite that of a universe in equilibrium as first conceived by Einstein, for later investigators, Friedmann, Lemaître and others have shown that such an equilibrium would be unstable. Space would immediately com. mence expanding or contracting with ever-increasing speed. We do not know what was the initial impulse which began the expansion. It may have been the starting of condensation in the primeval gas of which the universe is generally supposed to have consisted, but the suggestion, Sir James thinks, has not yet been strictly proved.

\section{Expansion of the Universe}

THe expansion of the universe expected by theory has been strikingly confirmed by radial velocity observations of the spiral nebulæ, which, we may remark, is discussed by Dr. R. O. Redman elsewhere in this issue (p. 836), but a serious difficulty immediately arises. The expansion is so fast that it cannot easily be reconciled with an evolutionary age of the universe greater than about $10^{10}$ years. Yet all other astronomical evidence requires an age of $10^{12}$ or $10^{13}$ years. The rate of expansion has been deduced theoretically by Eddington, who finds remarkable agreement with observation, at least so far as order of magnitude is concerned. If he can put his very daring calculations in a form which will command the general assent of mathematicians, they will provide a very strong confirmation of the whole theory of the expanding universe. Two other recent investigations have tried, in very different ways, to dispose altogether of the cosmical constant, the quantity which on Einstein's original theory fixed the amount of the large-scale curvature of the universe. Milne has supposed that the nebuiæ were formerly bunched together in a quite small region of space and endowed with motions which have produced both their present distances and their present velocities. This does not solve the age difficulty and Sir James feels also that the simplicity of this explanation has been achieved by assuming practically all that is to be explained. On the other hand, the recent work of Einstein and de Sitter suggests that really we know no reason which makes space have any inherent curvature. There seems to be a possibility that the universe is undergoing a series of expansions and contractions, in which case we have all the time we want for its evolution. This appears to Sir James to be the only possibility at present in the field which is not exceedingly difficult to reconcile with our general knowledge of astronomy.

\section{Crete and Mainland Greece}

Further evidence of the influence of Minoan Crete on the mainland of Greece after the fall of the Palace of Knossos was brought forward by Sir Arthur Evans in his lecture before the Hellenic Society on November 22. It has been derived from a number of inscriptions painted on vases discovered in a cellar by Prof. A. D. Keramopoulos, while excavating the Cadmeia of Thebes. These Sir Arthur has been allowed to examine and copy, and their publication has been reserved for him, by the Greek Archæological Society. The script, Sir Arthur said, answers in an overwhelming degree to that current in the latest phase of the Palace of Knossos as represented in more than 1,400 inscribed tablets. Out of about sixty signs gathered from the Minoan documents, no less than forty occur in the twenty. eight inscriptions from Thebes. In two instances the Theban inscriptions show the same signs as occur in the list of personal names in the inscription found at Knossos in 1902. Further, a comparison with the fragmentary inscriptions found on vases at Tiryns by the German excavators, and a few from Mycenæ, establish the identity of their script with that of Thebes. They also include a Knossian personal name. It may therefore be regarded as proved, Sir Arthur concluded, that in Mycenæan Greece of the fourteenth century B.C., the urban population spoke a language implanted from Crete, a language which in that island can be traced back to the third millennium B.C., and, if personal names count for anything, can be linked to the Carian races on the Anatolian side.

\section{Marine Biology of the University of Sydney}

DURING the past three years a scheme of oceanographic investigation has been initiated and conducted from the Department of Zoology of the University of Sydney, under the direction of Prof. William $J$. Dakin. The work commenced with an examination of the plankton and hydrographical conditions prevailing in the ocean waters off the entrance to Sydney Harbour. This is the first long-continued investigation of the plankton, that is, a study of the seasonal changes over a period greater than a year, to be made in Australian waters. In fact, little or nothing has been published regarding the seasonal changes in the plankton at any one station in the temperate waters of the southern hemisphere. The work has been greatly facilitated during the past year and a half by the acquirement of a small auxiliary yacht of about 12 tons (which has proved more suitable than a launch for ocean waters), and by the erection

No. 3292, VoL. 130] 